See Article page 1903.

\section{Commentary: When is the wrong thing just a little wrong?}

\author{
Gaetano Paone, MD, MHSA
}

A 62-year-old female patient with diabetes and class II angina undergoes elective cardiac catheterization, which demonstrates significant left main and 3-vessel disease. The cardiologist recommends coronary artery bypass surgery; however, the patient is a caregiver and wishes instead to undergo "ad hoc" percutaneous coronary intervention and stenting. In a well-written comprehensive review, $\mathrm{Ru}-$ bens and colleagues ${ }^{1}$ use this case example to consider the importance of patient preference on clinical decisionmaking and discuss the necessity to incorporate the principles of patient-centered care into the process of informed consent by considering not only the medical but also the emotional, mental, spiritual, social, and financial perspectives of the patient's needs. ${ }^{2}$

Offered alternatives, patients will often emphasize the more social aspects of the proposed treatment approach. Within the framework of patient-centered care, understanding and respecting the process that underlies the patient's choice-assuming it is clinically rational-can improve the provider-patient relationship and may positively impact patient outcomes. ${ }^{3,4}$ If we begin with an assumption that the patient has the capacity to make an informed decision regarding the relative risks, benefits, limitations, and alternatives to the proposed options, we must then assure the required information to make that decision is provided in a clear, unbiased, and fully forthcoming manner. This requisite dialogue of informed consent before any decision-making is not only ethically

\footnotetext{
From the Division of Cardiothoracic Surgery, Structural Heart and Valve Center, Emory University School of Medicine, Atlanta, Ga.

Disclosures: The author reported no conflicts of interest.

The Journal policy requires editors and reviewers to disclose conflicts of interest and to decline handling or reviewing manuscripts for which they may have a conflict of interest. The editors and reviewers of this article have no conflicts of interest.

Received for publication April 14, 2021; revisions received April 14, 2021; accepted for publication April 15, 2021; available ahead of print April 20, 2021.

Address for reprints: Gaetano Paone, MD, MHSA, Division of Cardiothoracic Surgery, Structural Heart and Valve Center, Emory University Midtown Hospital, 550 Peachtree St, NE, Davis-Fischer Bldg, 4th Floor, Atlanta, GA 30308 (E-mail: gaetano.paone@emory.edu).

J Thorac Cardiovasc Surg 2022;164:1907-8

$0022-5223 / \$ 36.00$

Copyright (c) 2021 by The American Association for Thoracic Surgery

https://doi.org/10.1016/j.jtcvs.2021.04.042
}

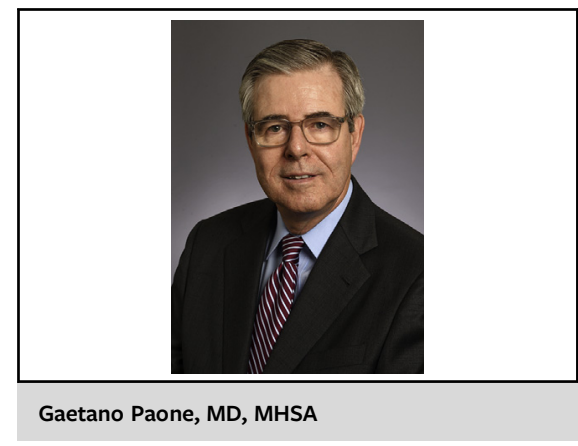

CENTRAL MESSAGE

Patient-centered care and

shared medical decision-making

respect patient autonomy and

choice. The physician remains

obligated to do no harm.

but also legally mandated as a component of the patient-physician relationship.

While very much a proponent of the heart team concept, I must question the authors' assertion that "medical teams can now quickly put together not just two people, but many interested parties instantaneously..." I might also ask what additional input is likely to change this patient's preference for percutaneous coronary intervention-with same or next-day discharge — as the most efficient path to full recovery and prompt return to the role of caregiver regardless of how one might describe potential longerterm advantages of coronary artery bypass surgery. Within this context, I suspect few would be surprised by this choice no matter what the qualifiers or how they are presented.

I believe the authors are correct in suggesting that "...cardiac surgeons and cardiologists enter medicine with a commitment to do the "right thing." As stated by Justice Cardoza," "Every human being of adult years and sound mind has a right to determine what shall be done with his own body..." If in fact we are required to honor a competent patient's desire to refuse treatment, however much to their assumed detriment, we are then certainly obligated to recognize their right to choose a treatment option we believe is suboptimal, as in the example presented. Respecting that choice when there is known or at least assumed clinical equipoise, or something close to it, is relatively easy. For all practical purposes, this is what shared decision-making should be. In contrast, as the authors acknowledge, the tenets of patient-centered care do not 
obligate us to provide a therapy we believe is unnecessary or irrational. Sometimes the wrong thing is not a little wrong, but simply wrong.

\section{References}

1. Rubens FD, Virani A, Coylewright M, Sathananthan J, Wood D. Balancing patient-centered care and evidence-based medicine in patients needing coronary revascularization. J Thorac Cardiovasc Surg. 2022;164:1903-6.
2. NEJM Catalyst. What is patient-centered care? 2017. Accessed April 12, 2021. Available at: https://catalyst.nejm.org/doi/full/10.1056/CAT.17.0559

3. Glickman SW, Boulding W, Manary M, Staelin R, Roe MT, Wolosin RJ, et al. Patient satisfaction and its relationship with clinical quality and inpatient mortality in acute myocardial infarction. Circ Cardiovasc Qual Outcomes. 2010;3:188-95.

4. Heidenreich PA. Time for a thorough evaluation of patient-centered care. Circ Cardiovasc Qual Outcomes. 2013;6:2-4.

5. Paterick TJ, Carson GV, Allen MC, Paterick TE. Medical informed consent: general considerations for physicians. Mayo Clin Proc. 2008;83:313-9.
See Article page 1903

\section{Commentary: Making decisions with all the evidence: What does the patient really want?}

\author{
Abdullah Malik, HBSc, ${ }^{a}$ \\ Rodolfo V. Rocha, MD, PhD, ${ }^{\mathrm{b}}$ and \\ Stephen E. Fremes, MD, MSc ${ }^{b}$
}

Modern health care practices have shifted away from the paternalistic model of "doctor knows best" to shared decision-making (SDM) between patients and physicians. In this model, best guideline practices derived from evidence-based medicine are now being applied within the individual context of a patient's values and preferences. ${ }^{1}$ SDM is desirable in all disciplines of medicine but especially in the context of coronary revascularization, where morbidity and mortality from one strategy (percutaneous coronary intervention $[\mathrm{PCI}]$ ) is lower in the short term but the alternative (coronary artery bypass grafting [CABG]) may offer better long-term survival and freedom from adverse events. ${ }^{2}$

From the ${ }^{\mathrm{a}}$ Temerty Faculty of Medicine, and ${ }^{\mathrm{b}}$ Division of Cardiac Surgery, Department of Surgery, Schulich Heart Centre, Sunnybrook Health Sciences Centre, University of Toronto, Toronto, Ontario, Canada.

Disclosures: The authors reported no conflicts of interest.

The Journal policy requires editors and reviewers to disclose conflicts of interest and to decline handling or reviewing manuscripts for which they may have a conflict of interest. The editors and reviewers of this article have no conflicts of interest.

Received for publication April 14, 2021; revisions received April 14, 2021; accepted for publication April 15, 2021; available ahead of print April 20, 2021.

Address for reprints: Stephen E. Fremes, MD, MSc, Schulich Heart Centre, Sunnybrook Health Sciences Centre, University of Toronto, 2075 Bayview Ave, Room H4 05, Toronto, Ontario, M4N 3M5, Canada (E-mail: stephen.fremes@ sunnybrook.ca).

J Thorac Cardiovasc Surg 2022;164:1908-9

$0022-5223 / \$ 36.00$

Copyright (c) 2021 by The American Association for Thoracic Surgery

https://doi.org/10.1016/j.jtcvs.2021.04.041
Check for updates

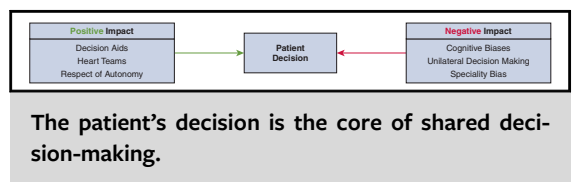

CENTRAL MESSAGE

For patients requiring coro-

nary revascularization,

patient-centered care is

paramount.

Rubens and colleagues ${ }^{3}$ navigate the challenges of arriving at the optimal decision for coronary revascularization using an illustrative case example of a patient who would clearly benefit from CABG but choses ad hoc multivessel PCI. Several key issues are highlighted when balancing best guideline practices and patient-centered care, including cognitive biases, practical challenges to SDM, and specialty bias. The informed consent process can be influenced by the cognitive biases experienced by the patient, including the phenomenon of focusing effect aversion, availability heuristic, and forecasting error. ${ }^{4-6}$ In the context of effective communication, clinician framing and structural inequities each have the potential to prevent fair SDM. Furthermore, when presenting treatment recommendations, surgeons, interventionists, and clinicians may carry biases about which approach is most suitable. ${ }^{7,8}$ Addressing these patient and provider issues systematically results from a compassionate stance that prioritizes patient autonomy. 